\title{
Looking for Evidence of Public Health's Role for Long-Term Evacuees
}

\author{
Barbara Clow ${ }^{1}$, Margaret Haworth-Brockman ${ }^{2 \star}$, Geneviève Boily-Larouche ${ }^{2}$, \\ Zeeshan Qadar ${ }^{2}$ and Yoav Keynan ${ }^{2,3}$
}

${ }^{1}$ Barbara Clow Consulting, Halifax, NS, Canada, ${ }^{2}$ National Collaborating Centre for Infectious Diseases, Rady Faculty of Health Sciences, University of Manitoba, Winnipeg, MB, Canada, ${ }^{3}$ Department of Medical Microbiology, Rady Faculty of Health Sciences, University of Manitoba, Winnipeg, MB, Canada

OPEN ACCESS

Edited by:

Francesco Della Corte Università degli Studi del Piemonte

Orientale, Italy

Reviewed by: Moran Bodas,

Sackler Faculty of Medicine, Tel Aviv

University, Israel Leonard Cole,

The State University of New Jersey, United States

${ }^{*}$ Correspondence: Margaret Haworth-Brockman margaret.haworth-brockman@ umanitoba.ca

Specialty section:

This article was submitted to Disaster and Emergency Medicine,

a section of the journal

Frontiers in Public Health

Received: 10 October 2018

Accepted: 17 January 2019

Published: 12 February 2019

Citation:

Clow B, Haworth-Brockman M, Boily-Larouche G, Qadar Z and Keynan Y (2019) Looking for Evidence of Public Health's Role for Long-Term Evacuees. Front. Public Health 7:15.

doi: 10.3389/fpubh.2019.00015
Many Canadians have had personal experience of a major emergency or disaster at some point in their lifetime and close to a third of those affected were evacuated from their homes or communities. Most evacuations have lasted less than 2 weeks, but in some instances, people have been displaced for months or years. For example, hundreds of residents evacuated following flooding in Lake St. Martin, Manitoba in 2011, remain displaced today. In order to learn more about the roles and responses of public health for long-term evacuees (LTES) in Canada, we conducted a narrative review of published English-language documents, beginning with literature specific to Canada and then expanding to include literature on other high-income countries. We found that while researchers have explored public health considerations in emergency preparedness, acute disaster management, and resettlement in these contexts there is a dearth of published evidence regarding the public health implications of prolonged evacuation and the public health responses to long-term evacuation in Canada and in other high-income countries. Because the public health needs of diverse populations of LTEs have not been fully investigated, it is likely that they are neither well-understood nor adequately addressed in public health policy and practice.

Keywords: public health, evacuation, disaster, long-term evacuees, Canada, emergency

\section{INTRODUCTION: DISASTER AND EVACUATION IN CANADA}

In a 2014 survey, 43\% of Canadians 15 years and older reported having experienced a major emergency or disaster in their lifetime and close to $30 \%$ of those affected have been evacuated from their homes or communities (1). Most of these evacuations last less than 2 weeks, but in some instances, people were displaced for months or years. For example, hundreds of residents evacuated following 2011 flooding in Lake St. Martin, Manitoba remain displaced today (2-5). The full extent of long-term evacuation in Canada is unknown because the Canadian Disaster Database tracks the number of evacuees, but not the duration of displacement. However, anecdotal evidence suggests that individuals in other Canadian communities, such as Lac-Mégantic, Quebec and Fort MacMurray, Alberta, have also experienced prolonged evacuation.

In recent years, communicable disease specialists and public health officers in Manitoba have observed that individuals and families evacuated to Winnipeg from their home communities following disasters, including those from Lake St. Martin, are regularly seeking primary care 
through emergency departments. This has raised concerns about the role of public health in managing infectious diseases, such as tuberculosis, blood-borne and sexuallytransmitted infections, and the on-going public health needs of evacuees who experience extended displacement. The National Collaborating Centre for Infectious Diseases (NCCID), which has a mandate for public health knowledge brokering in Canada, agreed to conduct a review of available literature on current and potential roles for public health during prolonged evacuation.

The following broad research question was formulated:

- "What is known, and what, if anything, is being done about the public health needs of LTEs in Canada?"

\section{METHODS}

Reviews are undertaken with the goal of synthesizing evidence available in published literature, but the choice of review method depends upon the nature of the research question $(6,7)$. Systematic reviews are designed to answer narrowly-defined research questions, often related to clinical practice or outcomes, and they are characterized by strict protocols for identifying, analyzing, and reporting on evidence. Narrative reviews, in contrast, are designed to address broad research questions, such as the state of knowledge about a concept, theory, or context, and to identify trends, patterns, and gaps in literature $(8,9)$. Because narrative reviews are intended to be iterative, rather than linear, it is difficult to apply strict protocols for searching, selecting, and analyzing evidence $(8,9)$.

The nature of our research question and the goal of understanding the scope of evidence on public health and longterm evacuation in Canada and other high-income countries determined that a narrative review would be the most appropriate methodology. In keeping with recommendations by Ferrari and others $(6,7,10)$ for transparency and rigor, we have described our approach to searching for and selecting relevant literature and to analysis.

We conducted a search for English-language, peerreviewed literature published between 2012 and 2018. "Long-term" was not defined in these searches to allow for diverse meanings to surface in the literature and to inform the analysis.

A preliminary screening search through Google Scholar was undertaken using search terms related to "public health," "disaster," "long-term," "internally-displaced," and "Canada." This search returned more than 20,000 documents, but a rapid scan of abstracts revealed that, in the Canadian context, the term "internally-displaced" was typically associated with individuals who had experienced long-term displacement in their countries of origin, as a result of natural disasters or conflict, before resettling Canada as immigrants and refugees. It did not refer to those experiencing long-term displacement from homes and communities within Canada. To test this result, we undertook an advanced search in Google Scholar that included the keyword "internally-displaced" and excluded the keywords "immigrant" and/or "refugee*" in combination with the other keywords related to public health and disasters in Canada. No relevant documents were identified through this search.

These results led us to adjust our search strategy, replacing keywords related to "internal-displacement" with "long-term evac*." A second screening search in Google Scholar using these keywords returned 731 documents and a rapid scan of abstracts indicated that some had potential relevance to the research question. This second search was repeated using PubMed Central and CINAHL to capture both the biomedical and sociological literature. References were hand-searched to identify relevant studies that fell outside of the search parameters. Additional targeted searches were conducted to identify literature on public health and LTEs from other high-income countries. Together, these searches identified a total of 456 documents with potential relevance.

All abstracts were reviewed, and the literature was analyzed thematically to identify content relevant to the research question as well as patterns and gaps in available evidence.

\section{RESULTS}

Although many documents in this dataset initially appeared relevant to the research question, upon review we found that none specifically or explicitly addressed the public health needs of and/or public health responses to LTEs in Canada. A single study from another high-income country - Japan - provided some evidence of where there may be a need as well as a role for public health among LTEs within Canada (11).

\section{Where Are the Gaps?}

The gaps in the literature on public health and long-term evacuation in Canada and other high-income countries fall into three main categories.

First, some studies broadly consider the long-term repercussions of emergencies and disasters in high-income countries, but they pay little or no attention to the effects of evacuation, prolonged or otherwise. For example, Noy and duPont's 2016 literature review on the long-term economic effects of Hurricane Katrina and the 1930s drought in the United States did not discuss the effect of evacuation or displacement (12). Similarly, a 2012 systematic review by Alderman et al. (9) on the health effects of flooding does not mention evacuation at all.

Second, even when researchers have focused on the detrimental effects of disasters and emergency evacuation on health and safety in Canada or other high-income countries, they have seldom considered the potential effects of prolonged vs. short-term displacement (9, 11, 13-17). For example, several studies of the flooding around Lake St. Martin, Manitoba described myriad adverse effects of displacement on Indigenous communities, but none examined the effects of the duration of evacuation (2-5). Likewise, Martin et al. (18) have explored the severe cultural and social effects of forced displacement on Indigenous communities in Canada, but they have not discussed whether or not prolonged 
evacuation has had a greater impact than displacements of shorter duration. Interestingly, this gap also existed in the international literature, despite being focused on emergencies such as Hurricane Katrina, and the Fukushima and Chernobyl nuclear disasters, that resulted in communities being evacuated for months or years $(11,13,14,17)$. According to Fussell, studies with evacuees from Hurricane Katrina ended after the first year and duration of evacuation was not treated as a variable of analysis (14). Researchers have noted a similar emphasis on the acute effects of displacement following the Fukushima disaster (11). Diminishing attention to the consequences of evacuation may be related to the costs of longitudinal research, the challenges of tracking evacuees over time, and other factors (11), but it has clearly contributed to a knowledge gap. As Fussell concluded, "much less is known about the in- and out-migrants to New Orleans, and even less is known about the long-term displaced" (14).

Third, research that explicitly considers the role of public health in disasters has tended to focus on emergency preparedness, evacuation decisions and processes, and the management of health during and immediately after a disaster (19-23). As Généreux et al. (24) have noted, "public health response during and after disasters has traditionally focused on protecting populations from chemical, biological, and physical threats, particularly among high-risk groups." By comparison, few studies have addressed the role of public health in ensuring the on-going health of LTEs. Once again, this finding is surprising because there is ample evidence that vulnerable populations-a public health priority-are likely to experience greater adverse effects from disasters and emergency evacuation $(4,9,20,25,26)$.

\section{Where Is There Evidence?}

This literature search found a single study that examined the impact of prolonged evacuation following emergencies in a highincome country. Nomura et al. (11) reported on the health of evacuees from the 2011 Fukushima nuclear disaster in Japan. The researchers observed that, 4 years after the disaster, long-term evacuees were more likely than non-evacuees and temporary evacuees to experience weight changes, sleep disturbances, and hyperlipidemia. They noted that risk of hyperlipidemia in LTEs might be related in part to reduced exercise and dietary changes based on real or perceived sustained risk of radiation contamination of air, water, and vegetation, and that public health has an on-going role to play in monitoring and communicating risk (11). They further noted that public health has a responsibility to ensure coordination of and access to services for LTEs.

\section{DISCUSSION}

In recent years, there has been increased interest in and concern about the impact of prolonged and permanent internal displacement on the well-being of individuals, families, and communities. As a result, there is growing body of literature on the physical and mental health effects of internal displacement in low-income countries and fragile or conflict states (2730 ), and on the public health needs of IDPs who resettle in Canada and other high-income countries as immigrants and refugees $(31,32)$. By comparison, little attention has been paid to populations that experience prolonged displacement from homes and communities within Canada or in other high-income countries. This gap may be a function of the reality that a relatively small number of emergencies in highincome countries result in long-term evacuation. In addition, the duration of displacement is difficult to predict at the onset of an emergency. It may also reflect the challenges of defining long-term evacuation and differentiating between the effects of short-term and protracted displacement. The challenges of keeping track of LTEs may also make it difficult to undertake longitudinal research with these populations. But one recent study suggests that those displaced for extended periods following disasters in high-income countries face many challenges and that public health has important roles to play in promoting and protecting the health and safety of LTEs (11).

\section{CONCLUSION}

Research demonstrates that the likelihood of emergencies associated with climate change is increasing alongside the rising incidence of human-created disasters and humanitarian crises $(33,34)$. According to the United Nations Office for the Coordination of Humanitarian Affairs, growing numbers of people are being displaced from homes and communities and both crises and displacements are lasting longer (35). Although much of this suffering happens in fragile and conflict states, high-income countries are not immune to disasters or, indeed, to long-term evacuation.

In Canada, emergency preparedness and response fall within the purview of public health (36), which suggests that public health is responsible for the health and safety of LTEs. Given the absence of research in this area, it is difficult to determine if and to what extent the public health effects of prolonged evacuation and the public health needs of long-term evacuees in Canada are being assessed, monitored, and addressed. Trends in the incidence of disasters and emergencies underscore the urgency of conducting more research to improve our understanding of prolonged displacement within Canada and in other highincome countries.

Greater awareness of this evidence gap is critical, both for inspiring new research and for supporting action to address the public health needs of LTEs in Canada. To this end, NCCID will be working with the other National Collaborating Centres for Public Health and public health actors to support knowledge exchange related to the on-going health and safety of LTEs. This will include working toward common definitions of "long-term" as well as how public health roles may continue after immediate and short-term emergency measures have wrapped up. An exploration of the opportunities to use health administrative and other data to augment what is known about the public health needs of diverse populations of LTEs is 
also proposed. These initial steps will be developed in concert with community leaders and public health officials to advance knowledge translation on environmental, economic, social, and policy implications for populations in Canada displaced long-term from their homes and communities as a result of disasters.

\section{LIMITATIONS}

This review considered only English-language published literature.

\section{REFERENCES}

1. Ibrahim D. Canadians' Experiences With Emergencies 2014. Juristat: Canadian Centre for Justice Statistics. Ottawa, ON (2016).

2. Ballard M, Thompson S. Flooding hope and livelihoods: Lake St. Martin First Nation. Can J Nonprofit Soc Econ Res. (2013) 4:43. doi: 10.22230/cjnser.2013v4n1a129

3. Ballard M, Martin D, Thompson S, Johnson A, Linton J, Lavallee B. A humanmade flood: When the umbilical cord to water and life becomes inimical to health. In: International Journal of Circumpolar Health - Proceedings. Oxon: Taylor \& Francis (2016). p. 30.

4. Thompson S, Ballard M, Martin D. Lake St. Martin First Nation community members' experiences of induced displacement: "We're like refugees". Refug Canada's J Refug. (2014) 29:75-87. Available online at: https://refuge.journals. yorku.ca/index.php/refuge

5. Thompson S. Flooding of first nations and environmental justice in manitoba: case studies of the impacts of the 2011 flood and hydro development in manitoba. ManLJ (2015) 38:220. Available online at: http:// themanitobalawjournal.com/

6. Grant MJ, Booth A. A typology of reviews: an analysis of 14 review types and associated methodologies. Heal Inf Libr J. (2009) 26:91-108. doi: $10.1111 / j .1471-1842.2009 .00848 . x$

7. Ferrari R. Writing narrative style literature reviews. Med Writ. (2015) 24:230-5. doi: 10.1179/2047480615Z.000000000329

8. Rother ET. Systematic literature review X narrative review. Acta Paul Enferm. (2007) 20:v-vi. doi: 10.1590/S0103-21002007000200001

9. Alderman K, Turner LR, Tong S. Floods and human health: a systematic review. Environ Int. (2012) 47:37-47. doi: 10.1016/j.envint.2012.06.003

10. Boell SK, Cecez-Kecmanovic D. On being 'systematic'in literature reviews. In: Formulating Research Methods for Information Systems. London: Springer (2015). p. 48-78.

11. Nomura S, Blangiardo M, Tsubokura M, Ozaki A, Morita T, Hodgson S. Postnuclear disaster evacuation and chronic health in adults in Fukushima, Japan: a long-term retrospective analysis. BMJ Open (2016) 6:e010080. doi: 10.1136/bmjopen-2015-010080

12. Noy I, duPont IV W. The long-term consequences of natural disasters-a summary of the literature. In: Working Papers in Economics and Finance. Wellington, AZ: School of Economics and Finance, Victoria Business School, Victoria University of Wellington (2016).

13. Bromet EJ. Mental health consequences of the Chernobyl disaster. J Radiol Prot. (2012) 32:N71. doi: 10.1088/0952-4746/32/1/N71

14. Fussell E. The long-term recovery of New Orleans' population after Hurricane Katrina. Am Behav Sci. (2015) 59:1231-45. doi: 10.1177/0002764215591181

15. Santavirta T, Santavirta N, Betancourt TS, Gilman SE. Long term mental health outcomes of Finnish children evacuated to Swedish families during the second world war and their non-evacuated siblings: cohort study. BMJ (2015) 350:g7753. doi: 10.1136/bmj.g7753

16. Gibbs L, Gallagher HC, Block K, Baker E. Post-bushfire relocation decisionmaking and personal wellbeing: a case study from Victoria, Australia. In: Planning for Community-based Disaster Resilience Worldwide. Routledge (2016). p. 355-78.

\section{AUTHOR CONTRIBUTIONS}

BC was the primary author. MH-B, GB-L, ZQ, and YK conceived the idea of the manuscript and made substantial contributions to all drafts.

\section{FUNDING}

NCCID is hosted by the University of Manitoba, which receives contribution funding from the Public Health Agency of Canada for NCCID. The views expressed herein do not necessarily represent the views of the Agency.

17. Genereux M, Maltais D, Roy M, Maillet MC, Gosselin J, Petit G. Post-disaster recovery, mental health and resiliency: the role of public health organizations. Prehosp Disaster Med. (2017) 32:S199-200. doi: 10.1017/S1049023X170 05210

18. Martin DE, Thompson S, Ballard M, Linton J. Two-eyed seeing in research and its absence in policy: Little Saskatchewan First Nation Elders' experiences of the 2011 flood and forced displacement. Int Indig Policy J. (2017) 8:6. doi: 10.18584/iipj.2017.8.4.6

19. Shimura T, Yamaguchi I, Terada H, Robert Svendsen E, Kunugita N. Public health activities for mitigation of radiation exposures and risk communication challenges after the Fukushima nuclear accident. J Radiat Res. (2015) 56:4229. doi: $10.1093 / \mathrm{jrr} / \mathrm{rrv} 013$

20. Powell T, Hanfling D, Gostin LO. Emergency preparedness and public health: the lessons of Hurricane Sandy. JAMA (2012) 308:2569-70. doi: 10.1001/jama.2012.108940

21. Hasegawa A, Ohira T, Maeda M, Yasumura S, Tanigawa K. Emergency responses and health consequences after the Fukushima accident; evacuation and relocation. Clin Oncol. (2016) 28:237-44. doi: 10.1016/j.clon.2016. 01.002

22. Runkle JD, Brock-Martin A, Karmaus W, Svendsen ER. Secondary surge capacity: a framework for understanding long-term access to primary care for medically vulnerable populations in disaster recovery. Am J Public Health (2012) 102:e24-32. doi: 10.2105/AJPH.2012. 301027

23. Kouadio IK, Aljunid S, Kamigaki T, Hammad K, Oshitani H. Infectious diseases following natural disasters: prevention and control measures. Expert Rev Anti Infect Ther. (2012) 10:95-104. doi: 10.1586/eri. 11.155

24. Généreux M, Petit G, Roy M, Maltais D, O’Sullivan T. The "Lac-Mégantic tragedy" seen through the lens of the EnRiCH Community Resilience Framework for High-Risk Populations. Can J Public Heal. (2018) 109:261-7. doi: 10.17269/s41997-018-0068-z

25. Peacock WG, Gladwin H, Morrow BH. Hurricane Andrew: Ethnicity, Gender and the Sociology of Disasters. New York, NY: Routledge (2012). doi: 10.4324/9780203351628

26. Bolin B, Kurtz LC. Race, class, ethnicity, and disaster vulnerability. In: In: Rodriguez H, Quarantelli EL, Dynes RR, editors. Handbook of Disaster Research. Vol. 643. New York, NY: Springer.

27. Blanchet K, Ramesh A, Frison S, Warren E, Hossain M, Smith J, et al. Evidence on public health interventions in humanitarian crises. Lancet (2017) 390:2287-96. doi: 10.1016/S0140-6736(16)30768-1

28. Quinn J, Stoeva P, Zelený T, Nanda T, Tomanová A, Bencko V. Public health crisis: the need for primary prevention in failed and fragile states. Cent Eur J Public Health (2017) 25:171-6. doi: 10.21101/cejph. a 4671

29. Owoaje ET, Uchendu OC, Ajayi TO, Cadmus EO. A review of the health problems of the internally displaced persons in Africa. Niger Postgrad Med J. (2016) 23:161-71. doi: 10.4103/1117-1936.196242

30. Silove D, Ventevogel P, Rees S. The contemporary refugee crisis: an overview of mental health challenges. World Psychiatry (2017) 16:130-9. doi: 10.1002/wps. 20438 
31. Fazel M, Reed RV, Panter-Brick C, Stein A. Mental health of displaced and refugee children resettled in high-income countries: risk and protective factors. Lancet (2012) 379:266-82. doi: 10.1016/S0140-6736(11)60051-2

32. Pottie K, Greenaway C, Hassan G, Hui C, Kirmayer LJ. Caring for a newly arrived Syrian refugee family. CMAJ (2016) 188:207-11. doi: $10.1503 / \mathrm{cmaj} .151422$

33. Coleman L. Frequency of man-made disasters in the 20th century. J Contingencies Cris Manag. (2006) 14:3-11. doi: 10.1111/j.1468-5973.2006.00476.x

34. Institute SR. Natural Catastrophes and Man-Made Disasters in 2017: A Year of Record-Breaking Losses [Internet]. Vol. 2018, Sigma (2018). Available online at: https://reliefweb.int/sites/reliefweb.int/files/resources/sigma1_2018_en.pdf

35. United Nations Office for the Coordination of Humanitarian Affairs. Global Humanitarian Overview 2019 [Internet]. Vol. 2018 (2018). Available online at: https://www.unocha.org/sites/unocha/files/GHO2019.pdf
36. Public Health Agency of Canada. About the Agency [Internet]. (2017) Available online at: https://www.canada.ca/en/public-health/corporate/ mandate/about-agency.html

Conflict of Interest Statement: The authors declare that the research was conducted in the absence of any commercial or financial relationships that could be construed as a potential conflict of interest.

Copyright (C) 2019 Clow, Haworth-Brockman, Boily-Larouche, Qadar and Keynan. This is an open-access article distributed under the terms of the Creative Commons Attribution License (CC BY). The use, distribution or reproduction in other forums is permitted, provided the original author(s) and the copyright owner(s) are credited and that the original publication in this journal is cited, in accordance with accepted academic practice. No use, distribution or reproduction is permitted which does not comply with these terms. 